\title{
Commentary: Balloons are not for angioplasty alone: A novel occlusion technique for stroke prevention
}

\author{
Christopher R. Burke, MD, and Pavan Atluri, MD
}

\author{
From the Division of Cardiothoracic Surgery, University of Pennsylvania, Philadelphia, Pa. \\ Disclosures: Authors have nothing to disclose with regard to commercial support. \\ Received for publication Oct 23, 2018; accepted for publication Oct 23, 2018; available ahead of print Nov 30, \\ 2018 \\ Address for reprints: Pavan Atluri, MD, Perelman Center for Advanced Medicine, East Pavilion, 2nd Floor, 3400 \\ Civic Center Blvd, Philadelphia, PA 19104 (E-mail: pavan.atluri@uphs.upenn.edu). \\ J Thorac Cardiovasc Surg 2019;157:1346-7 \\ $0022-5223 / \$ 36.00$ \\ Copyright $(5) 2018$ by The American Association for Thoracic Surgery \\ https://doi.org/10.1016/j.jtcvs.2018.10.112
}

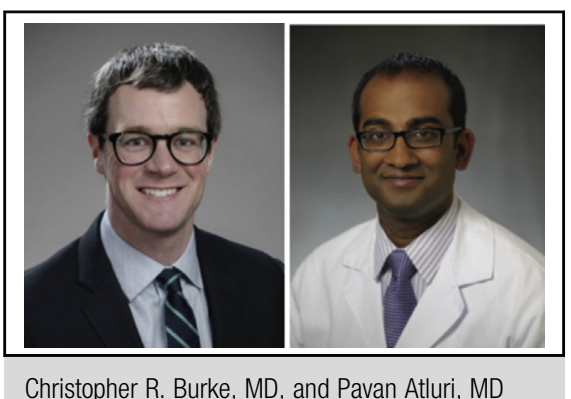

Christopher R. Burke, MD, and Pavan Atluri, MD

\section{Central Message}

Balloon occlusion techniques of the LSA may play an important role in stroke prevention during endovascular arch repair.

See Article page 1336. tality after thoracic endovascular aortic repair (TEVAR). This is especially true with "hybrid" aortic arch aneurysm repairs, with stroke rates as high as $8 \%$ reported previously. ${ }^{1}$ Many of these patients have significant medical comorbidities, including previous stroke, peripheral vascular, and coronary artery disease, and resultant aortic atheroma and calcifications. It is well known that endovascular procedures in the aortic arch result in significant cerebral embolization; in fact, in the SENTINEL trial evaluating transcatheter cerebral embolic protection devices in patients who have undergone transcatheter aortic valve replacement, embolic debris was found within the filters of $99 \%$ of patients. ${ }^{2}$ Furthermore, investigation into stroke distribution within patients receiving TEVAR has demonstrated a predilection for posterior cerebral events, which carry greater morbidity than anterior circulation strokes. ${ }^{3}$ Therefore, prevention of embolic stroke during TEVAR is of paramount importance to the cardiovascular surgeon.

In this month's issue of the Journal, Seike and colleagues ${ }^{4}$ present a case series investigating the safety and efficacy of left subclavian artery (LSA) balloon occlusion during debranching TEVAR. The authors present a case series of debranching TEVAR in patients comparing LSA balloon occlusion with a control group. The LSA was balloon occluded before wire or catheter manipulation of the aortic arch during the TEVAR. The LSA was then plugged or coil embolized after TEVAR deployment. Several different cerebral debranching procedures were used throughout the study period. There were no strokes in the cohort receiving LSA balloon occlusion, compared with a $7.9 \%$ stroke rate in the control group. Of note, mortality rates at 2 and 4 years postprocedure were significantly lower in the LSA balloon occlusion group. These betweengroup differences persisted even after propensity score matching.

There is little doubt that endovascular repair of aortic arch pathology will increase substantially in the coming years. Single branch arch grafts are already in use, ${ }^{5}$ and several dual branch grafts (for total endovascular arch repair) are in clinical trials with preliminary data showing promising results. ${ }^{6}$ Open replacement of the aortic arch carries a risk of stroke of approximately $10 \%,{ }^{7,8}$ and minimizing risk of stroke will be a major determinant of the long-term success of endovascular arch therapies. Therefore, the recognition that a majority of strokes during TEVAR occur within the posterior circulation (and results in greater morbidity than anterior strokes) underscores the need for cerebral protection strategies during these procedures. This can be accomplished by various LSA revascularization strategies with occlusion of the proximal LSA, along with other novel interventions such as the balloon occlusion technique described by Seike and colleagues. ${ }^{4}$ One could even envision the use of cerebral embolic protection devices, similar to those used in transcatheter aortic valve replacement, during endovascular arch repair. Only time will tell in what direction the field is headed. But one thing is clear: As more endovascular therapies are applied in the aortic arch, with an increasingly complex patient population with significant atheromatous and calcific disease, the need for novel strategies to combat stroke will only intensify.

\section{References}

1. Bavaria J, Vallabhajosyula P, Moeller P, Szeto W, Desai N, Pochettino A. Hybrid approaches in the treatment of aortic arch aneurysms: postoperative and midterm outcomes. J Thorac Cardiovasc Surg. 2013;145(3 Suppl):S85-90.

2. Kapadia SR, Kodali S, Makkar R, Mehran R, Lazar RM, Zivadinov R, et al. Protection against cerebral embolism during transcatheter aortic valve replacement. $J$ Am Coll Cardiol. 2017;69:367-77. 
3. Ullery BW, McGarvey M, Cheung AT, Fairman RM, Jackson BM, Woo EY, et al. Vascular distribution of stroke and its relationship to perioperative mortality and neurologic outcome after thoracic endovascular aortic repair. J Vasc Surg. 2012; 56:1510-7.

4. Seike Y, Matsuda H, Inuoue Y, Omura A, Uehara K, Fukuda T, et al. Balloon protection of the left subclavian artery in debranching thoracic endovascular aortic repair. J Thorac Cardiovasc Surg. 2019;157:1336-45.e1.

5. Desai ND, Hoedt A, Wang G, Szeto WY, Vallabhajosyula P, Reinke M, et al. Simplifying aortic arch surgery: open zone 2 arch with single branched thoracic endovascular aortic repair completion. Ann Cardiothorac Surg. 2018;7:351-6.
6. Spear R, Haulon S, Ohki T, Tsilimparis N, Kanaoka Y, Milne CP, et al. Editor's choice - subsequent results for arch aneurysm repair with inner branched endografts. Eur J Vasc Endovasc Surg. 2016;51: 380-5.

7. Martens A, Beckmann E, Kaufeld T, Umminger J, Fleissner F, Koigeldiyev N, et al. Total aortic arch repair: risk factor analysis and follow-up in 199 patients. Eur J Cardiothorac Surg. 2016;50:940-8.

8. Kazui T, Yamashita K, Washiyama N, Terada H, Bashar AH, Suzuki K, et al Aortic arch replacement using selective cerebral perfusion. Ann Thorac Surg. 2007;83:S796-8; discussion S824-31. 